\title{
Construct of the Full Removable Prosthetic Based on Biofunctional System in Edentulous Patients
}

\author{
Edit Xhajanka ${ }^{1}$, Merita Bardhoshi $^{2}$, Koco Gjilo $^{3}$, Agron Meto ${ }^{4}$, \\ Redona Collaku ${ }^{5}$, Aida Meto ${ }^{6}$ \\ ${ }^{1}$ Professor at the Faculty of Dental Medicine, Prosthodontic Department, Tirana, Albania \\ ${ }^{2}$ Professor at the Faculty of Dental Medicine, Surgery Department, Tirana, Albania \\ ${ }^{3}$ Lecturer at the Faculty of Dental Medicine, Prosthodontic Department, Tirana, Albania \\ ${ }^{4}$ Professor at the Medicine University of Aldent, Endodontics Department, Tirana, Albania \\ ${ }^{5}$ Faculty of Dental Medicine, Prosthodontic Department, Tirana, Albania \\ ${ }^{6}$ Lecturer at the Faculty of Dental Medicine, Restorative Dentistry Department, Tirana, Albania
}

\begin{abstract}
The median age of the patients wearing full removable dentures is rising. Their jawbones are more and more atrophied. In order to construct an efficient total prosthesis, we based on the Biofunctional System, elaborated by U.Stuttgen. The preparation process of these dentures was built on the principles of Guided Functional Movement. The aim of our study was to construct a full removable prosthesis according to the bilateral balanced occlusion with no alterations, interferences, deformities and to compare it with the conventional prosthesis in terms of stability, function, achievement of balanced occlusion, strength, mechanical resistance, decubitus, sore and aesthetics. As a study material, we included 245 patients treated by our University Clinic, at the Department of Prosthodontic, observed in 7 years long period. We divided patients into two groups: in the first one 133 patients treated by using biofunctional prosthesis and 112 patients were part of the second group treated with the conventional dentures. We concluded and compared the results of the prosthesis systems in both groups based on the check up immediately after putting on the dentures and 7 years later. As a result, the biofunctional prosthesis had a high advantage compared to the conventional ones in all terms.
\end{abstract}

Keywords: atrophied, biofunctional system, jawbones, total prosthesis, stability.

\section{Introduction}

Biofunctional Prosthesis System (BPS) is also called biogenic or biofunctional, because of the ability to construct dentures which are really similar to the natural elements they substitute, fulfilling this way aesthetics , functional and phonetic demands of the patient $[6,10,15,16,25]$. The biofunctional prosthetic system is compound of a wide range of appliances, artificial teeth and materials combined in each working session starting from impression taking up to the final design of the denture. In this system, the whole work up process is built on the individual data recorded on the patient itself. In Biofunctional Prosthesis, it is paid importance to the different anatomical structures of the jaw and achieving a bilateral balanced occlusion. This provides a uniform distribution of the occlusal forces and minimizes the resorption of residual ridge [2,22,23]. An increase in average age of the population has caused a rise in the contingent of patients wearing full removable dentures. Lejoyeux et.al, [8,21] highlight that full dentures make up for $33.2 \%$ of all total prosthesis. According to Zarb and Bolender [9] nowadays, $1 / 3$ up to $1 / 2$ of the population over 65 years old are edentulous, women being the most common ones. The most advanced system nowadays is the Biofunctional System, whose priorities are the principles of bilateral balanced articulation $[3,10,11,16]$.

Our goals were to:

\section{Aim Of The Study}

1- Define the positive effects and advantages of Biofunctional Prosthesis shows compared to the traditional ones;

2- Construct total biofunctional prosthesis according to the principles of bilateral balanced occlusion with no alterations, deformities or interferences;

3- Construct full dentures that ensure a greater stability and better, faster adaption than conventional prosthesis.

\section{Materials And Methods}

During a 7 years long period we treated 245 patients of different age, 35-50 years old, 50-65 years old and above 65 years old (average age:57 years old). 
We divided our patients into 2 groups:

- In the first group were included 133 patients, wearing biofunctional prosthesis in bilateral balanced occlusion;

- In the second group were included 112 patients wearing conventional full dentures in unilateral balanced occlusion.

The working method in preparing the biofunctional prosthesis is completely different compared to the conventional one. In both, our groups of patients we conducted in short terms check up in the following 2 weeks up to 3 months, comparing the results and clinical terms in each group. In 5-7 years following long term check-ups we evaluated the clinical parameters in terms of the effect of the denture in the prosthetic area like: continuing resorption of the residual ridge and the state of the mucosa underneath it.

Our study results were based in different markers like: Passive stability and Functional Stability of the denture, decubitus, and interferences. It is also important to emphasize the fact that the patient is adjusted at a faster rate using these types of dentures, where the incidence of denture stomatitis is lower and the need for readjustments is greatly diminished.

\subsection{Clinical Material}

The preparation process begins with the impression technique, which in the biofunctional prosthesis is unique and special.

1- Anatomical impression (or functional depending on the dentist's choice) is also followed by a second impression taking process in central occlusion through a centric tray. In this way, we managed to have an individual tray and bite-blocks which are exact or almost exact to the central occlusal position. We use this individual tray to take a functional compressive impression with both jaws joint in central occlusion (Fig. 1 a-e).

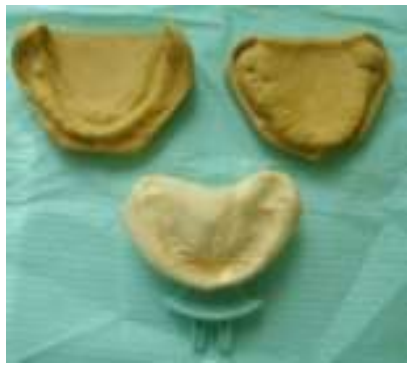

$\mathbf{a}$

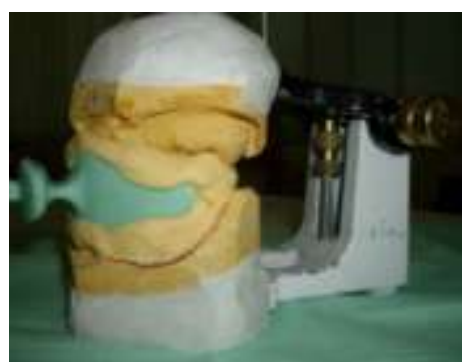

b

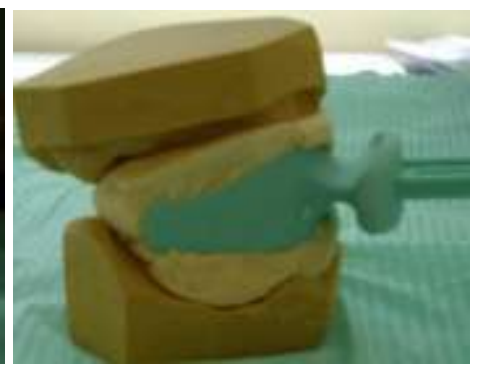

c

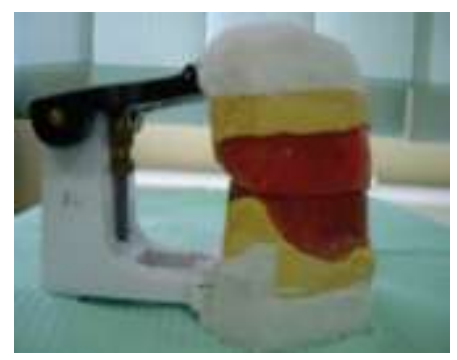

d

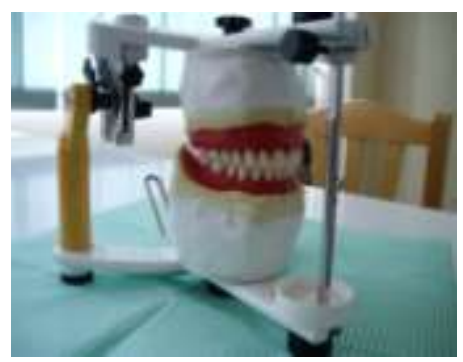

e

Fig.1: $\boldsymbol{a}$-Impression and working casts, $\boldsymbol{b}$ - positioning of casts in central tray, $\boldsymbol{c}$-repositioning in articulator, $\boldsymbol{d}$ preparing the individual trays and bite templates in central, $\boldsymbol{e}$ - wax up denture trial.

As functional impression technique, we used for the first time the individualization and personal registration of the Postdam Area. This concept is primarily introduced in this technique which upon now was recognized as a single line; the Postdam or Vibration Area represents the area where the soft and hard palate combine. In this area, the mucosal tissue shows a high resilience. The Postdam makes up for the most important zone in determining the stability and posterior adhesion of the upper denture.

\subsection{The Palate Sealing Technique}

A previous phase of individualizing the Postdam Area and a following phase of recording it:

- Individualization the Postdam means defining the exact posterior borders of the denture. 
- Recording the Postdam means defining the depth of the posterior borders into the palatal mucosal tissue, at the fusion area between the soft and hard palate.

\section{We used this technique in the functional recording of the Postdam Area:}

First of all the functional impression was taken. Then the posterior vibrating line was marked in the patients mouth through a copying pencil (by pronouncing the AH sound) and the anterior line by blowing the nose with closed nostrils. The mucosal area between the two lines represents the vibration zone (Postdam).

We repositioned the functional impression in the oral cavity and applied pressure in it. Both lines appeared on the impression material. In between these lines we applied a small amount of material, same as at the functional impression and we repositioned the tray back into the oral cavity. Then, we told to the patient to pronounce a long and light AH sound in order to rise up the soft palate and let this space get filled by the material we applied in the vibrating zone. This will also be reflected in the mucosal surface of the future denture and suppress the mucosal tissue in the vibration area, by acting as a barrier for air pressure, similar to the gouge process in practice.

The advantage of this technique consists in the pressure of the denture applies into the mucosa individually recorded, based on the soft tissue resilience of the patient and not in random ways such as the scraping process (Fig.2 a-c).

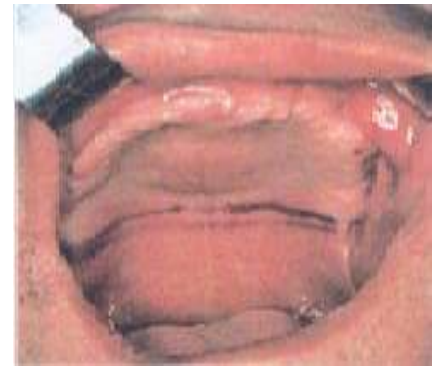

a

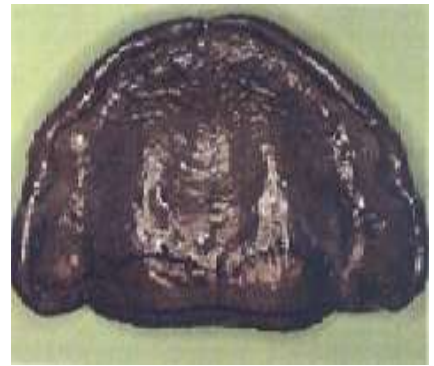

b

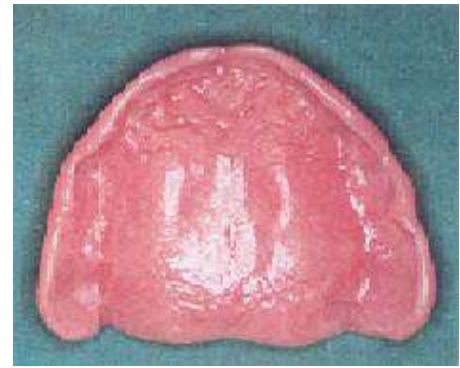

c

Fig 2: $\boldsymbol{a}$ - high resilience vibration zone, $\boldsymbol{b}$ - functional recording of the Postdam area, $\boldsymbol{c}$ - reflection of the vibration zone in the final denture.

In defining the central occlusion we were based on anatomical criteria in terms of the level of the occlusal plane (tongue relation, alveolar mandible tubercular, etc) as well as phonetic criteria which were considered secondary in the previous clinical practice. We chose the graphic method in defining the central occlusion through a Gnathometer (Gothic Arch). This is an entirely physiological technique which is based on forming a pathway of mandible movements $[12,14,20]$. In the basal plate of one of the templates (the plate must always be constructed on resin) we pinned down the gnathometer's plate, tinted with colored wax. In the other jaw's basal plate we pinned down the plate with the pointing needle. We asked the patient to carry out propulsive, retropulsive and lateral movements of the mandible. In this way the track of all movements was achieved. The intercrossing of all pathways determined the point of central occlusion. In this final position we pinned down both templates eventually.

In aligning the teeth in bilateral balanced occlusion we used the Stratos 200 Articulator (Fig. 3 a-c).

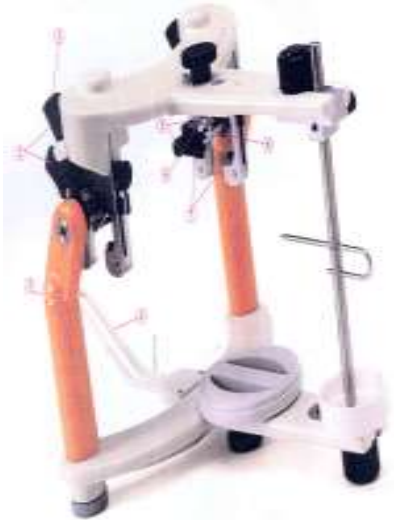

a

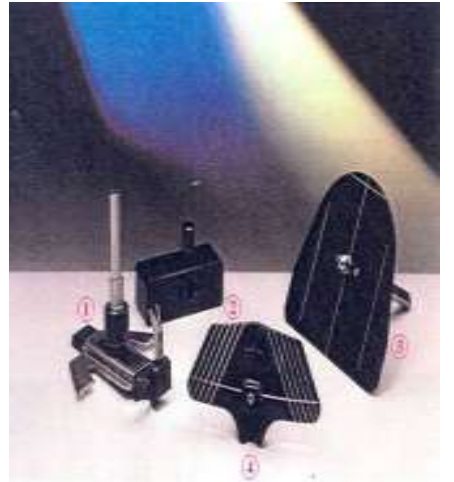

b

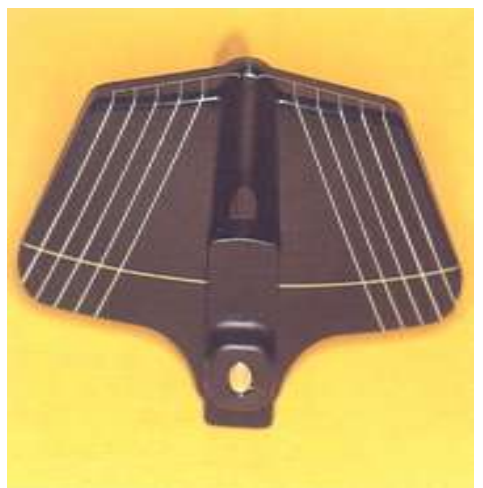

c

Fig.3: a-Articulator Stratos 200, b- its accessories, $\boldsymbol{c}$-Bi-dimensional Guide. 
The Stratos 200 Articulator is an Archon-type articulator, semi-adjustable, equipped with a wide range of accessories $[2,3,6,15]$. In this one you can register individual data from the patient through the facial bow. In aligning teeth in bilateral balanced occlusion and achieving simultaneous contact during different movements, we used a special accessory; the Bi-dimensional Guide (Fig.3c).

In difficult clinical cases, such as extreme size of cranium and jaw and pathological occlusion, we paid special attention to patient's individual data recording through the Facial Bow. In order to achieve a highly aesthetics, we took into consideration choosing the right artificial teeth based on many methods and parameters (gender, size, shape of face, shape of maxilla, physical constitution of the patient. The posterior teeth were chosen according to functional requirements $[1,8,9,18]$. We preferred the N-type of posterior teeth, with reduced cuspid morphology $\left(\right.$ angle $\left.=22^{\circ}\right)$.

\subsection{The alignment of teeth in Stratos 200 Articulator}

During the final preparation process of BPS denture, in order to keep constant bilateral balanced occlusion relation, we established a polymerization procedure as in the SR-IVOCAP pressure system [5,22,24]. In this system, the polymerization is preceded in layers from down-up. This provides no deformities of the denture after polymerization, avoids alterations of occlusal relation, interferences, pores in resin and leads to a more exact adhesion of the denture and mucosa (Fig.4) [3,6,10,19].

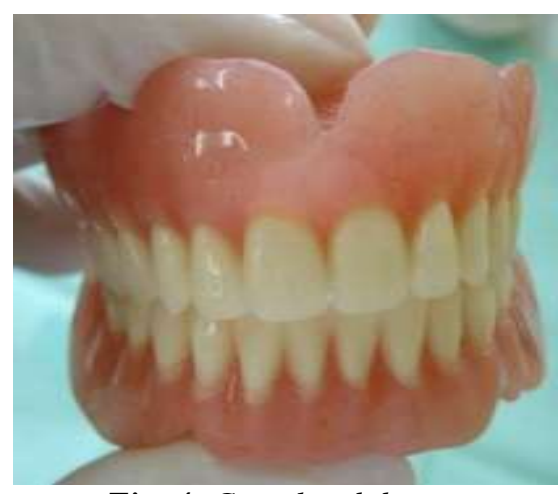

Fig. 4: Completed denture.

During the final try out of the completed denture, we verified the multi-point contacts in different movements of the mandible in order to ensure the bilateral balanced occlusion.

\section{RESULTS AND DISCUSSION}

The analysis and conclusions of our work were based on the results accomplished from treating 245 patients through complete removable denture; 112 conventional dentures and 133 Biofunctional dentures. We divided the patients according to the age into three groups: 35-50 years old, 50-65 years old and above 65 years old. We also analyzed into details the types of jaw atrophy in groups, degree of resorption, type of teeth used, sorting patients according to variations of Postdam Area etc.

The results achieved in this process we sustained in to the following index:

1- Subjective Data Evidence

2- Clinical Data Evidence

3- Adjacent Results

- Subjective data are those obtained from the patients themselves who refer that the adjustment process was faster in Biofunctional Prosthesis.

- Clinical data: According to our continuous check up on our patients, we evaluated the adaption in both types of denture, the chewing process, functional stability, decubituses, aesthetics, phonetics etc.

- Adjacent results: We observed our patients from the implementation period up to 3 months. In the early check up (within 10 days) we evaluated these results:

Stability: Nearly 2 weeks after treatment, we examined the stability of the denture in passive and functional condition. We classified the Stability into 4 categories according to the patients review: very good, good, sufficient, not good.

According to our results $[4,17,19,24]$ and those of foreign authors $[1,2,7,8,12,13]$ we noticed that in terms of stability during mastication, phonetic and rest, was higher in Biofunctional Prosthesis than in conventional 
dentures. As you can see, in BPS the stability is better in $33.1 \%$ of the cases compared to $19.7 \%$ in traditional dentures.

Decubitus: Another evaluation parameter was the presence of pression sores in the treated patients. We considered as a decubitus more than 1 episode of pressure sore. We think that the presence of these lesions is related to the technique of polymerization (The SR-IVOCAP avoids the shrinking and alteration of the denture) and also to the dismissal of functional overload in specific areas during mastication, as a result of unbalanced occlusion.

In many aspects we can see the advantage of Biofunctional Prosthesis System to the Conventional Dentures.

\subsection{Distant results}

We achieved these results from our checkups in 7 years following period. Alveolar process resorption (residual ridge). In biofunctional prosthesis, due to the bilateral balanced occlusion, we achieve a uniform distribution of forces in all prosthetic area. This minimized the resorption of residual ridge and the need for further rebasing procedures.

\section{CONCLUSIONS}

Biofunctional Prosthetic reduced in a great rate the cases of pressure sores, stomatitis and oral candidiasis. In BPS due to bilateral balanced occlusion, it was achieved a higher stability of the denture in function and resting condition in $86.4 \%$ of the cases, compared to $60 \%$ in conventional denture cases. Noticing the advantage of BPS in each term, we consider it to be far more efficient than conventional denture in every aspect. It optimally fulfills the aesthetic, functional and phonetic demands of the patients. The preparing procedure of the BPS in a bilateral balanced occlusion decelerated the resorption process compared to the atrophied ridge in conventional dentures.

\section{REFERENCES}

[1]. Hayakawa I., La protesi totale, principi e tecniche, 2001.

[2]. Buchel R, Frick H., Scheiblich R., Schleich H., Ivoclar Prosthetic System, 1992.

[3]. Igorlic R., The biofunctional prosthetic system, 2003.

[4]. Koci N., Proteza e plote dhe fusha e saj, Monografi 2005.

[5]. Scotti R., D' Elia A., Corso propedeutico preclinico di protesi totale, 2000.

[6]. Fonollosa M., BPS- The Biofunctional Prosthetic System-Reflect, 1/2003.

[7]. Garotti, Barbetti, Milano, Pavesi., Odontotecnica pratica 2, 1990

[8]. Lejoyeux. J., Prothese complete, 1, 2, 3. 1976, 1978, 1979.

[9]. Zarb, Bolender- Prosthodontic treatment for edentulous patients; Complete dentures and implant- supported prostheses, 2005

[10]. Grundler, Stuttgen., Die totalprothese IV, 1995

[11]. Garotti G., Sistema di montagio. Executive- La quintessenza odontotecnica, 3bis/2003, 257- 289.

[12]. Bortolotti L., Garotti G., Registrazione del rapporto intermascellare nei pazienti edentuli, PROtech 6/2001, 23-32.

[13]. Bortolotti L., Garotti G., Protesi mobile: piano di trattamento, polimerizzazione e consegna delle protesi, PROtech 1/2002, 29-37.

[14]. McNeill C., L'occlusione; basi scientifiche e pratica clinica, Scienza e tecnica dent. 1999.

[15]. Petrullo M., Considerazioni sull' utilizzo dell'articolatore Stratos 200 in protesi totale, Il nuovo laboratorio odontotecnico nr. 71999.

[16]. Shaffner T., Il sistema protesico biofunzionale, Dental labor nr.2/3/4 Mea 1998.

[17]. Koçi N., Prognoza e qëndrueshmërisë së protezës së plotë në nofullat pa dhëmbë. Revista stomatologjike "Apolonia", 4-2000.

[18]. Stanley J. Nelson - Wheeler's dental anatomy, physiology and occlusion, 12/2002.

[19]. Keraj F., Rritja e lartësisë së okluzionit qendror në protezat totale me metodën e zakonshme të polimerizimit.2005

[20]. Christensen GJ., Removable prosthodontics: a forgotten part of dentistry, Alpha Omegan, 3/2006.

[21]. Eitner S., Wichmann M., Pilot study on the psychologic evaluation of prosthesis incompatibility using the SCL-90-R scale and the CES-D scale. Int J Prosthodont. 9-10/2006.

[22]. Kivovics P., Jahn M., Borbely J., Frequency and location of traumatic ulcerations following placement of complete dentures. Int J Prosthod. 7-8/2007.

[23]. Piermatti J., Balanced occlusion versus canine guidance for complete dentures. SADJ 2/2004.

[24]. Xhajanka E., Protezat Biofunksionale. Dizertacion 2009.

[25]. Cuman, Masnata, Nannini., La protesi totale secondo la metodica di Slavicek, 2005. 